\title{
Correction to: Do initial financial conditions determine the exit routes of start-up firms?
}

\section{Yuji Honjo ${ }^{1} \cdot$ Masatoshi Kato $^{2}$}

Published online: 4 July 2019

(C) Springer-Verlag GmbH Germany, part of Springer Nature 2019

\section{Correction to: Journal of Evolutionary Economics https://doi.org/10.1007/s00191-019-00623-0}

The original version of this article unfortunately contained mistakes.

On page 18, the sentence "The first-order terms of $M C R$ are positive at least at the $1 \%$ significance level in all the columns in Table 6."

should be:

The first-order terms of $M C R$ are positive at the $1 \%$ significance level in columns (i), (ii), and (iv) in Table 6.

On page 18, the sentence "Moreover, while the interaction term of $\ln E$ and $M C R$ is insignificant in column (iii), that of $E / F$ and $M C R$ is negative at the $1 \%$ significance level in column (v)."

should be:

Moreover, while the interaction term of $\ln E$ and $M C R$ is insignificant in column (iii), that of $E / T F$ and $M C R$ is positive at the $1 \%$ significance level in column (v).

On page 21, the sentence "The sign of the estimated coefficients for merger is opposite to that for failure."

should be:

The sign of the estimated coefficients for merger is similar to that for failure.

Pulisher's note Springer Nature remains neutral with regard to jurisdictional claims in published maps and institutional affiliations

The online version of the original article can be found at https://doi.org/10.1007/s00191-019-00623-0

Yuji Honjo

yhonjo@tamacc.chuo-u.ac.jp

1 Faculty of Commerce, Chuo University, 742-1 Higashinakano, Hachioji, Tokyo 192-0393, Japan

2 School of Economics, Kwansei Gakuin University, 1-155 Uegahara Ichiban-cho, Nishinomiya, Hyogo 662-8501, Japan 